\title{
ENACTING SELF AND SCIENTIFIC PERSONAS: MODELS FOR WOMEN HEALTH PROFESSIONALS IN DR. S. JOSEPHINE BAKER'S FIGHTING FOR LIFE
}

\author{
AMY RuBEns
}

\section{ABSTRACT}

In this essay, I call on scientific persona and autobiographical discourse theory to examine Dr. Sara Josephine Baker's 1939 autobiography Fighting for Life. Through this framework, I consider how Baker and other U.S. women health professionals conceived of individual identity and collective persona during the early twentieth century. Baker helped to revolutionise well-baby and well-child care in the U.S., and in Fighting for Life, she relates the genesis and evolution of her groundbreaking work. Like her contemporaries, Baker was engaged in the research, practice, teaching, and administration of medicine and public health. Presently, scientific persona has been theorized as a conglomerate of dispositions, practices, and characteristics that are associated with scholar-practitioners of the human and natural sciences; it therefore offers a novel lens for the individual and collective fashioning of women health professionals like Baker whose work traversed disciplines and institutions. By considering how Fighting for Life, as autobiography, facilitates Baker's conception of self and persona, I show that Baker adopts prevailing personas for women health professionals as well as women working in other fields. At the same time, Baker in her autobiography also emphasizes why and how these models transform in actual practice. Thus, scientific personas tend to emerge as subtle variations of previous forms, while Baker's autobiography also bears witness to the rise of new personas for women health professionals, as demonstrated by her radical reconfiguration of expert knowledge and scientific motherhood.

\section{KEY WORDS}

Authorship; Career; Gender; Lifewriting; Medicine; Public Health

\section{INTRODUCTION}

Between 1885 and 1919, New York City's infant survival rate improved markedly, and Dr. Sara Josephine Baker, who held degrees in medicine and public health, played a significant role in this transformation (Meckel 1990, p. 89; Petrash 2016). Her achievements, press coverage, connections to high profile cases, lecture appearances, and scientific and lay publications, including her 1939 autobiography Fighting for Life, made Baker a household name (Leavitt 
1996; Parry 2006). Baker's exact motivation for writing her autobiography is unknown, as she destroyed her personal papers before her death in 1945 (Epstein 2013, p. xviii). However, between World War I and World War II, women's vocationally focused retrospectives were enormously popular in the U.S. (Applegarth 2015). In fact, when Baker's autobiography was first published, it garnered a rave review in the New York Times, and when it was re-published in 2013, it enjoyed a similarly favorable review in the same publication (Feld 1939; Zuger 2013). Still, one thing remains clear in the reading of Fighting for Life: Baker wanted to explain how she revolutionised well-baby and well-child care in New York City, the U.S., and arguably, other parts of the world.

Through Fighting for Life, I examine the scientific personas associated with Baker and other (mainly white) American women health professionals during the late nineteenth and early twentieth centuries. Lorraine Daston and H. Otto Sibum (2003) first theorized scientific personas as the "collective ways of thinking, feeling, judging, perceiving, [and] working" associated with "the human as well as the natural sciences" (p. 1,5). Due to forces that enabled and constrained women's entrance into medicine during the fin de siècle, many women health professionals like Baker simultaneously were engaged in the research, practice, teaching, and administration of medicine and public health (Fee \& Greene 1989; Meckel 1990; MorantzSanchez 1985). Consequently, scientific persona becomes an apt framework for understanding how such work was collectively conceived. Indeed, scientific personas do not always correspond to particular professions or institutions but instead "emerge and disappear within specific contexts" (Daston \& Sibum 2003, p. 3). Because scientific personas must achieve a certain degree of social recognition, they tend to surface as variations of long-standing archetypes and rarely appear de novo (Algazi, 2016; Daston \& Sibum 2003; Paul 2016). Studying personas "encourages historians of the sciences and humanities to examine the transmission of repertoires of [scientific] selfhood throughout disciplines and timeframes" (Paul 2016, p. 137). Therefore, examining the personas of women health professionals like Baker who traverse disciplinary boundaries and professional obligations in the course of a day-let alone a careermight prompt us to reconsider (1) what constitutes "scientific" personas, and (2) how such personas are adopted, discarded, and forged anew.

Although personas are cultural "templates" or "models," to borrow some terms from Algazi (2016), they hold considerable importance for individuals (p. 12). Scientific personas transform, and thus are deeply integrated in, the ways scientists think, behave, produce scholarship, and physically style themselves (Bosch 2016; Daston \& Sibum 2003, p. 3; Paul 2016). Thus, as Herman Paul (2016) asserts, personas and individual identity "can never be considered apart from each other" (p. 142). As I will explain, autobiography at once records and facilitates the interaction between persona and identity (Eakin 1985; Smith 1995), a notion Paul (2016) himself acknowledges when he asserts the inseparability of "persona" and "person" (p. 142 , 143). Considering collective persona and individual identity together and within autobiography underscores how they are constituted by historical and structural forces; gender, class, race, sexuality, and their intersections; personal characteristics; and subjective experience (Algazi 2016; Bosch 2016). It is in this vein that I approach scientific personas and individual identity in Baker's Fighting for Life: How does this text, as autobiography, reflect and call into being the forces impelling Baker's self-conception as a typical yet exceptional early-twentieth century woman health professional? After all, as a queer woman working in not only medicine but also the nascent field of preventive public health, Baker could not easily "assume a preexisting persona" (Algazi 2016, p. 31; Hansen 2002).

I begin exploring Baker's enactment of self and scientific personas in Fighting for Life by more deeply theorizing genre's role in this process; by way of illustration, I show how Baker's 
construction of her younger self in Fighting for Life anticipates the personas for women health professionals with which she will contend in subsequent parts of the text. These models, at their extreme, connected women's motivation for studying medicine with either financial advancement and personal achievement, on the one hand, or moral obligation and a natural affinity for caretaking, on the other (Morantz-Sanchez 1985). Baker largely adopts these competing personas in the retelling of her early professional career, but she reinterprets them in more radical ways when she recounts her later, more significant interventions in preventive public health. In articulating these personas, Baker perhaps bears witness to the creation of new models for women health professionals. Contra to contemporary views of Baker's legacy, one such persona coalesces in opposition to the theory of scientific motherhood, which held that only empirically founded knowledge espoused by experts should guide the care of infants and children, no matter if they were sick or well (Apple 2006 p. 37; Grant 1998). To conclude my assessment of scientific personas in Fighting for Life, I reevaluate Baker's text as an example of what Risa Applegarth (2015) calls "vocational autobiography", an autobiographical genre by and for women that was popular during the early to mid-twentieth century (p. 531). Through this lens, Baker can be seen as crafting personas for women professionals who aspire to executive roles in a variety of fields. But, unlike other (female) vocational autobiographers, Baker refuses to privilege hard work as the primary factor for her professional success. Rather, as I will explain, she also acknowledges the importance of luck and a pioneering spirit in order to emphasize that professional women were constrained by stereotypical notions of gender, but not always absolutely.

\section{UNDERSTANDING IDENTITY AND PERSONAS IN AUTOBIOGRAPHY}

Before I examine how Baker adopts, confronts, and perhaps creates personas for women health professionals in Fighting for Life, I want to return to the earlier claim that autobiography records and facilitates the interaction between person (individual identity) and scientific persona (cultural template or model). Conventionally speaking, Fighting for Life might provide exclusive access to facts about Baker's personal and professional lives that are not available anywhere else, especially considering that she destroyed all of her personal papers (Epstein 2013, p. xviii). Yet, Western autobiography (no matter how one demarcates its inception) cannot be reduced to the objective, chronological recording of one's life (Eakin 1985, p. 202; Smith 1995). Autobiography is a performative account of a subject's identity formation and trajectory. By performative, I mean that autobiography is a view or an account of one's life that is shaped by personal motivations and outside pressures as well as the filter of memory (Johnson 2011; Kehily 1995; Smith \& Watson 2002). In fact, regarding the latter point, autobiographers often acknowledge the slippage between their recollected reality, others' memories, and objectively verifiable events; Philippe Lejeune (1989) calls this stylistic device the "referential pact," and it can be glimpsed throughout Baker's Fighting for Life (p. 22). Its first appearance occurs in chapter one when Baker concludes a series of anecdotes about growing up in Poughkeepsie, New York. She relates, "I do not mean that all this happened when I was a [very young] child. It is all mixed up in my memory, for until I was seventeen, the world was a unit with no gaps or turning points" (Baker 1939, p. 9). In making this admission, Baker essentially acknowledges that Fighting for Life is an earnest yet flawed retelling of her past, as she understands it.

The referential pact not only linguistically signals the autobiographer's good intentions. According to Paul John Eakin (1985), it also illustrates why autobiographical accounts often imperfectly correlate with the historical record: autobiography reflects the writer's selfconception at the present (i.e., writing) moment (p. 5). Sidonie Smith (1995) concurs and 
asserts that the autobiographical self is the result and not the antecedent of remembering and narrating one's life; autobiographical storytelling, in other words, brings a version of one's self into existence (p. 18). These selves are culturally inscribed and bear traces of "symbolic interactions within and between collectivities...[and] [s] ocial organizations" (Smith \& Watson 2002 , p. 10). Autobiography, then, is a mediated view of one's life that simultaneously facilitates the performance of identity - the "form and content of the self in any individual"-as well as the elucidation of persona-the "model of the self in culture" (Eakin 1985, p. 206-207).

\section{NarRating Childhood and the Retrospective Emergence of Personas in FIGHTING FOR LIFE}

If autobiography engenders identities and personas that are influenced by the writer's present self-conception, then Baker's autobiographical recollection of her childhood anticipates the personas she aligns herself with and against in subsequent parts of Fighting for Life. Many of these personas are rooted in the dominant templates for white women physicians during the nineteenth and early twentieth centuries. Regina Morantz-Sanchez (1985) offers a cogent articulation of these personas by drawing from the private and public discourse of female physicians, including Baker's Fighting for Life. Specifically, she explains that these models existed on a continuum: At one end of the extreme, medicine was seen as a path to financial success and professional renown; this more masculine perspective coalesced as a "culture of professionalism" that valued "individualism, scientific objectivity...personal achievement, and careerism" (Morantz-Sanchez 1985; p. 5). At the other end of the spectrum, medicine was seen as a moral call to duty, and women who heeded it naturally would bring more "cooperation, nurturing, purity, and social concern to their work" (Morantz-Sanchez 1985 p. 186; 5). Some women also felt called to medicine because of early experiences with illness (Morantz-Sanchez 1985, p. 107). Baker's conception of her childhood encompasses both of these models, as she portrays herself as a sympathetic child whose upbringing and early experiences with illness anticipate her professional achievements as an adult, but not always in the expected ways.

Interestingly, Baker begins Fighting for Life-and therefore the story of her childhoodby reinforcing the assumption that some women physicians were inherently sympathetic and moral. Here, she relates a dubious yet rhetorically effective anecdote about her "impulse to try to do things about hopeless situations" (Baker 1939, p. 1). She was six years old and was "dressed up for some great occasion" in a "white lacy dress" (Baker 1939, p. 1). While she waited for her mother, Baker retreated to her family's horseblock to play when she suddenly encountered a thin, "hungry[-]looking" African American girl (1939, p. 1). The girl's plight "struck [Baker] right over the heart," as she "could not bear the idea that [she] had so much and [the girl] had so little" (1939, p. 1). Without hesitation, Baker took off all her clothes and gave them to the girl. The racially troubling valence of this recollection aside, it nevertheless establishes that Baker conceptualises herself as both selfless and willing to act to improve the lives of others.

Baker also is quick to deny in Fighting for Life the common assumption that, as a successful, unmarried woman, she must have had an unhappy or bizarre childhood. On the contrary, she relates that "it would have taken a pretty demanding, not to say peevish, kind of child to fail to adjust to the family environment in which [she] was reared" (Baker 1939, p. 2). For one, the "gay nineties" of Baker's youth were "an ample, affluent time," and her family was "reasonably well to do as wealth went in Poughkeepsie" (1939, p. 2, 6). Perhaps more importantly, her parents cultivated a wholesome, nurturing atmosphere. During the summers, the family vacationed in the nearby Catskill Mountains; in the winter when the Hudson River froze, the Bakers enjoyed ice skating, and sled races; throughout the year, they would receive 
students from nearby Vassar College for dinner and other social events (Baker 1939, pp. 3, 7, 9). Although Baker's upbringing was wholesome and active, it was not overly indulgent: having a "formal education" was valued in her family just as much as "good times and active gaieties" (1939, p. 22). Taken together, these recollections illustrate that Baker "was reared in a thoroughly conventional tradition and took happily to it," and in relating her childhood in this way, she counters the assumption that her success as an adult was connected to a "suppressed" or strange upbringing (1939, p. 2).

Paradoxically, Baker's recollection of her youth also underscores the extent to which she was exposed to the unconventional. On the home front, her father encouraged her to pursue traditionally masculine activities, like sports, while her Great Aunt Abby instilled in her a "thrilling skepticism" and the notion that "it is possible to question the unquestionable" (Baker 1939, p. 3; 21). Perhaps Abby's influence was inevitable: Abby was a Quaker, and from Baker's perspective, "Quakers have a way of being different without anyone's minding" (1939, p. 20). Iconoclastic institutions also seem to have shaped Baker's identity formation. As a young person, she attended a "highly unusual" school that was orchestrated by two women from a home they shared (Baker 1939, p. 22). The school had "no graded classes, no marks or reports, no examinations, [and] not even any commencement exercises" (Baker 1939, p. 23). In addition, while visiting relatives in Dansville, New York, young Baker would encounter the staff and patients of Jackson Sanitarium, a health hospital that was known for its unusual policies regarding diet (e.g., applesauce, hard biscuits, and water) and dress (e.g., Bloomers and short hair for women) (Baker 1939, p. 15). Her retelling of these meetings reflects an implicit admiration for the ways in which the facility embraced non-normative notions of health and gender. Importantly, Baker regards her exposure to the non-traditional as positively supporting her development. At the same time, the unconventional aspects of her upbringing did not jeopardize her ability to conform to social expectations, either: Baker was a self-described tomboy who excelled at sports, but she also took great pride in her cooking and sewing abilities (1939, p. 13). Thus, from an early age, Baker courted the traditional and non-traditional—and without complication.

While Baker begins the first chapter of Fighting for Life describing her earliest childhood memories, she concludes it by relating how a traumatic event put her on the path to adulthood: In 1889 and when she was sixteen-years old, her brother died of typhoid. Her father died of the same disease two years later, and the family immediately was thrown into dire financial straights. To Baker, who was on the precipice of entering college, "it was immediately evident that somebody would have to get ready to earn a living for all three" of the remaining family members, and so it was decided that she should abandon her plans to attend Vassar College, take the family's remaining savings, and "go to New York and study to be a doctor" (1939, p. 25). Overall, her account of her childhood evinces a picture of a sympathetic young woman whose wholesome yet idiosyncratic upbringing allowed her to flourish. When confronted by unexpected tragedy, she let pragmatism and ambition guide her along a new path.

\section{Inhabiting Prevailing Personas for Women Physicians}

Baker's autobiographical recollection of her childhood foreshadows the scientific personas she engages with to conceputalise her early years as a private physician who also worked as a part-time public health inspector. In light of my earlier claims about autobiography's ability to construct—and not simply reveal—individual identity and collective personas, I want to revisit some passages in Fighting for Life that Morantz-Sanchez (1985) examines in her historical study of women physicians in the U.S. These passages illustrate that Baker conceives of her fledgling professional years as being shaped by the same forces that 
encouraged other women to become physicians: financial need and personal achievement, on the one hand, and moral duty, on the other. However, as I will show, through Baker's engagement with the autobiographical act, she advances variations of these personas that, while subtle, are linked to her personal characteristics, life experiences, and historical moment in significant ways.

Women during Baker's era were pulled and pushed towards prevailing personas for physicians for various reasons. As noted earlier, women identified personal experiences with illness as a motivation for practicing medicine (Morantz-Sanchez 1985, p. 107). In addition, connections made during medical school likely influenced women's conceptions of their work as physicians. Baker, for instance, attended the Women's Medical College of New York, which was founded by Dr. Elizabeth Blackwell, who Baker calls "the fountainhead of all medical training for American women" (1939, p. 31). For Blackwell, medicine was a moral calling, but for Dr. Mary Putnam Jacobi and Dr. Marie Zakrzewska, who were employed as professors at the Women's Medical College of New York during Baker's enrollment, medicine was an intellectual pursuit that demonstrated women were on equal footing with men (Bittel 2009; Morantz-Sanchez 1985; Tuchman 2009). During Baker's studies, she also completed a course with Dr. Annie Sturges Daniel on "The Normal Child," which, ironically, she initially failed because she found it boring (1939, p. 42).

Larger cultural and structural forces also exerted considerable pressure on the personas women physicians inhabited. Women's awareness of medicine as an attainable, profitable career; connections to reform movement and culture; and increased access to medical schools all influenced the lenses through which women physicians like Baker collectively were viewed and defined themselves (Fee \& Greene 1989; Moldow 1987; Morantz-Sanchez 1985). These forces and the personas they helped shape were further compounded by women's racial, ethnic, and socioeconomic positions as well as their status as women (Moldow 1987; Wu 2009). Indeed, although women's access to medical schools was improving, their acquisition of positions in medicine remained stagnant. As a consequence, many women physicians turned to public health work during the early twentieth century. While this work appealed to women who were interested in reform movements, it also offered a low barrier for entry: men tended to eschew public health work because it lacked prestige (Fee \& Greene 1989; Morantz-Sanchez 1985).

In Fighting for Life, Baker's recollection of her early professional years evinces a self and persona that are indeed guided by ambition, financial need, and moral duty, but her remembrances also contextualize this presentation by highlighting how women's practice of medicine neither was a guaranteed path to financial security nor an assured means of achieving progressive social change. Her humorous description of starting a private practice in New York City with her friend, Dr. Laighton, is instructive in this regard. The women decided to specialise in obstetrics in order to build their clientele, but against the advice of family and friends, they located their practice in New York City instead of a rural area where costs and competition from other (male) physicians would have been lower (Baker 1939, p. 52). So, although Laighton's family "gave [them] enough money to furnish the place and equip [the] office," they made so little profit in the first year that it was a wonder they did not "starve" (Baker 1939, p. 52). Of course, "being young," Baker relates, "they were incapable of worrying" and instead used their "mother-wit" to determine how they might use their training and status as physicians to "supplement [their] incomes" (1939, p. 53).

In the critical and biographical literature, one often-cited example of this "mother-wit" involves Baker and Laighton's employment for a major life insurance company ('Dr. S. Josephine 
Baker' 2003; Morantz-Sanchez 1985; Parry 2006). Yet, many of these accounts overlook Baker's explanation in Fighting for Life of how "a call from a much too persistent life-insurance agent...accidentally" brought about this opportunity (1939, p. 53). Hoping to end the call quickly, Baker and Laighton "asked if the [salesman's] company had a woman doctor to examine [them] if [they] did take out insurance" (1939, p. 54). Hearing that no such provision existed, the women decided to sell the company their expertise, and eventually, they convinced the company's executives to hire them as medical examiners for prospective female clients. As a result, the two women not only earned a "steady stream of profitable fees" with which to subsidise their private practice, but they also created a lucrative, new specialty for women physicians (Baker 1939, p. 54). Baker's recollection of her early professional years thus reinforces and reshapes the notion that many women physicians approached medicine as a pathway to personal renown and financial success. Her remembrances especially highlight how medical practice in the early twentieth century often perpetuated financial need for women. Consequently, women were forced to rely on their ambition, ingenuity, and determination to survive.

As noted earlier, some women physicians and nurses during the early twentieth century met their financial needs by turning to public health work (Fee \& Greene 1989; MorantzSanchez 1985). Baker was no exception, and when she relates her entrance into public health work in Fighting for Life, she transfers some of the frames she relied on to make sense of her childhood and early years as a physician to her endeavors in this field. Specifically, she emphasizes her motivation to succeed, earn a living, and contribute to the public good as being guided by inward desires and external circumstances. Consider that Baker first became interested in public health work "by accident" when she noticed a newspaper advertisement for a position with New York City's Health Department: the pay would “[double [her] first year's rate of income" (1939, p. 54). After passing the required civil service exam, Baker was offered "a summer position in hunting out and looking after sick babies" in the tenement neighborhoods of New York City where the "heat, the smells, [and] the squalor made [them] something not to be believed" (1939, p. 57).

Baker's entrance into public health, however, was not only motivated by financial need; like many of her contemporaries, she also conceives of her work as a moral imperative. Baker relates in Fighting for Life that her position with the health department appealed to her "long...acquired...burning sense of the injustice in the world" (Baker 1939, p. 61). Moreover, she returned to her seasonal public health work year after year-and despite securing a higherpaying summer job and having responsibilities to her growing private practice-because she felt something should be done about the "mass misery" of the tenements (Baker 1939, p. 59, 60). The problem was staggering, and during her first summer on the job, the "babies and small children who never really had a chance to live...swelled the death rate to fantastically macabre proportions" (Baker 1939, p. 60). To be sure, they "were not just cold statistics" to her (Baker 1939 , p. 83). Rather, they reflected a complex problem that encompassed parents who did not know any better and, more insidiously, corrupt and inefficient institutions that magnified "problems of food, clothing, [and] shelter" (Baker 1939, p. 62). Frustrated, Baker strayed from counting deaths and cases of disease to "looking for healthy babies too" (1939, p. 58). She wanted to "tell their mothers how to care for them" to keep them well, but they found the concept of preventive health, which "had hardly been born yet and had no portion in publichealth work," to be strange, and as a result, Baker "might as well have been trying to tell them how to keep it from raining" $(1939$, p. 83; 58).

Baker persisted in bringing preventive public health to the urban poor, and in 1908, she was appointed the first chief of New York City's Bureau of Child Hygiene. She closed her private 
practice five years later to transition to the bureau full time until her retirement from civil service in 1923 ('Dr. Josephine Baker' 2003). In relating this stage of her public health career in Fighting for Life, Baker continues to rely on competing personas for women in medicine. She acknowledges that she eventually approached her public health work with a certain degree of ambition. In fact, she pursued a doctorate in public health while teaching in the same program (and enduring horrific treatment from her all-male students) because she knew the degree would legitimise her expertise and ensure her continued professional success (Baker 1939, pp. 162, 190; 'Dr. S Josephine Baker' 2003). Nevertheless, Baker's desire for professional acclaim did not compromise her sense of moral obligation: she detested her male colleagues who advanced through the ranks but did little to improve the lives of an extremely vulnerable population, a position she reinforces by declaring she was no "Elsie Dinsmore" of the health department (Baker 1939, p. 61). Dinsmore, the heroine of almost thirty popular children's novels written during the late nineteenth century, would have been familiar to Baker's readers (Hardman 1988). Whereas Dinsmore solidified her middle-class positioning by "relinquish[ing] a great deal of spiritual and moral control to men," Baker improved her station in life as well as that of others by confronting patriarchal systems of power (Hardman 1988, p. 70).

\section{Articulating Personas for Women Health Professionals in Public Health}

As Baker divulges more concerning her work as a public health inspector and administrator, she necessarily refigures the dominant personas for women physicians to a greater degree; perhaps less surprisingly, this engagement may encompass new personas for women health professionals. Furthermore, and as I have been claiming, Fighting for Life draws attention to the ways external forces and Baker's subjective experiences influenced her articulation of scientific personas. To illustrate this claim, I will focus on Baker's characterisation of preventive public health workers as scientific experts who can discover empirically founded practices yet nevertheless embrace intuition in the service of their goals. Baker's uncomplicated celebration of instinct and rationalism subverts the late-nineteenth century belief that women health professionals lacked the cognitive ability to think scientifically and instead had to rely on their "natural" inclination towards intuitive thinking (Skinner 2014, p. 147). As a consequence of this deficit, women physicians supposedly only could "apply[] existing medical knowledge in a rote manner," thus making their contributions to medicine merely derivative (Skinner 2014, p. 147).

Baker takes aim at this idea in Fighting for Life on multiple occasions. Perhaps most visibly, she describes the methodologies and results of her thesis The Relation of Classroom Ventilation to Respiratory Disease Among School Children in great detail (Baker 1939, p. 162). This is curious for two reasons: First, by this point in the text, Baker already had dismissed her doctoral degree in public health as a formality. Second, such specialised information likely would have been immaterial to her 1939 reading public. Thus, by including such an exhaustive description of her thesis, Baker indicates that women health professionals were well versed in scientific methods and could use them to advance their field. Nevertheless, women health professionals also were guided by intuition and other forces opposing rational thought. Baker and her team, for instance, reduced the infant mortality rate in New York City's "foundling" (i.e., orphan) hospitals by fifty percent in one year by "work[ing] out the right methods by trial and error" (1939, p. 124). Circumstances simply required it: they "had to make [their] own way and evolve [their] own procedure, without precedents to help or to bother [them]" (Baker, 1939, pp. 124-125). What is more, trial and error seems to work hand-in-hand with intuition: the "foundling-hospital situation" "had been vaguely in [Baker's] mind for some time [before it] began to take definite form" (1939, p. 121, 119). 
In addition to placing rational thought and intuition on an equal plane in rethinking personas for women health professionals, Baker reconfigures the locus of intuition and expert knowledge in the delivery of preventive health services. Her recollection of the Little Mothers' Leagues, a school-based program for young girls she helped develop, especially illustrates Baker's attempts to rethink the designation of "expert." Before addressing this point, I would like to describe the history and purpose of the Little Mothers' Leagues. First launched as a pilot program in 1908, the Little Mothers' Leagues endeavored to provide working-class and immigrant girls in New York City with practical training in all aspects of well-baby care (Baker 1939, p. 134; Division of Child Hygiene 1925, 'Planning to Teach' 1909). League meetings were facilitated by trained experts who led participants in hands-on activities, such as composing skits and conducting demonstrations with realistic props (Baker 1939, p. 135; Kleinschmidt 1926, p. 133; Rennert 1916, p. 309). Early versions of the Little Mothers' Leagues were so successful that Baker secured their installation in public and parochial schools across New York City (1939, p. 135; 'Little Mothers Write Playlets' 1910). By 1916, Little Mothers' Leagues were being established throughout New York State and other parts of the U.S. (Division of Child Hygiene 1925; Rennert 1916, p. 306-207).

In some ways, the popularity of Baker's Little Mothers' Leagues is not surprising, as "the girl child of the poor" had been a target of reform for some time. Whereas people like John Spargo saw the "little mother" as a "menace," Baker viewed her as the product of her parents' structurally determined circumstances (1939, p. 132; 1907, p. 38). As Baker explains it, the little mother was "forced by poverty to take over the care of the next-youngest child because her mother" was busy keeping a job that "fe[d] the whole family" (1939, p. 132). Baker, then, does not necessarily oppose the "little mother" system. In fact, she acknowledges that having older siblings care for younger siblings

works out very well in the remoter islands of the Samoan group...But Orchard Street in New York City is not Samoa and the hygienic emergencies of bringing up a child in an east side gutter are not the same as those in a culture composed of clean sea-water and palm-groves [sic]. ${ }^{1}$ (Baker 1939, p. 132)

Because Baker could not reform the structural and environmental conditions that created the little mother, she instead "work[ed] realistically with the raw materials and situations at hand" by transforming these young girls "into something that suited [her] purpose" (1939, p. 133). For Baker, the little mother would be an emissary of knowledge in two ways. On the one hand, she would relay her knowledge of well-baby care to her mother, who perhaps would more readily accept her daughter's advice as opposed to that of a visiting nurse. On the other hand, the little mother would be better equipped to care for her own children once she became a mother, and her knowledge would be passed on to future generations (Baker 1939; Kleinschmidt 1926).

Scholars have been critical of Baker's Little Mothers' Leagues and their indoctrination of working-class and immigrant girls in the philosophy of "scientific motherhood" (Apple 2006; Grant 1998). Within this framework, mothers were "people in desperate need of education, and the best education came from physicians, who taught mothers to look to them for advice in all aspects of childcare," including the treatment and prevention of illness (Apple 2006, p. 37). Scientific motherhood thus encouraged an unflagging acquiescence to expert authority, and what is more, all mothers, regardless of class status, were regarded as deficient in their ability to independently ascertain the health needs of their children (More 1999, p. 75). While baby-care manuals and guidebooks gently ushered middle-class audiences into scientific motherhood, programs like the Little Mothers' Leagues supposedly functioned as a much more forceful and menacing vector of this ideology for the working and immigrant classes (Apple 2006, p. 47; Grant 1998, p. 82-83). 
Baker's anecdotes about the Little Mothers' Leagues in Fighting for Life contradict these claims in subtle yet important ways. ${ }^{2}$ Through these remembrances, she implies that well-baby and well-child care should encompass scientific and instinctual knowledge that lay persons, no matter their class status, can employ with experts and in contextually appropriate ways. Baker's description of some original compositions produced by league members bears out this claim. One composition involved a "list of twelve 'don'ts' for mothers of small children" that offered axioms like "don't leave the baby [to] sit on the stove" and "don't give the baby herring...and sour cucumbers" (Baker 1939, p. 136). Other compositions included a play titled "Hear Not the Advice of a Neighbor; or How Babies Die" and a sketch that shows a league participant teaching her mother about the proper solid foods for babies (Baker 1939, p. 136). Baker acknowledges that, although these compositions seem strange, they evince "a healthy realism and a solid sense of tenement conditions...which still assures [her] that [they] trained [the] Little Mothers pretty well and that [the Little Mothers] had a lot of common sense of their own to start with" (1939, p. 136-137).

Curiously, these ideas as well as the play "Hear Not the Advice of a Neighbor; or How Babies Die" appear almost verbatim in an unattributed 1910 article from the New York Times. In commenting on the compositions of league members, an anonymous worker from New York City's Health Department states:

I know...that there is a lot of most amusing material to be gathered here...[T]he children have a naïve way of expressing what they learn, but they have the truth of it. Giving cabbage and pickles to babies isn't merely a humorous ideait's an issue among the children of the tenements. They make a practical application of what they learn... ('Little Mothers Write Playlets' 1910)

The issue of plagiarism notwithstanding, these passages from Fighting for Life and the New York Times demonstrate that Baker's little mother is not necessarily a passive receptacle for the knowledge of credentialed experts, as it coalesced under scientific motherhood. Rather, she is an active participant in preventive public health, as she reframes her acquired scientific knowledge to account for her material conditions, personal experiences, and inherent capacity for mothering (Baker 1939, p. 134).

Baker's characterisation of well-baby and well-child care in Fighting for Life advances a model for women health professionals that reconfigures scientific, expert, and intuitive ways of knowing. Consequently, because this template opposed the hegemonic dominance of scientific motherhood, it might be seen as the emergence of a new persona for early-twentieth century women health professionals. Just as significantly, Baker's articulation of personas for women health professionals also illustrates the ways in which autobiography records and facilitates the interaction between persona and identity. Baker began Fighting for Life by charting her identity formation. She portrayed her young self as being guided by traditional and non-traditional beliefs regarding gender, family structures, education, religion, and wellness. It is no surprise, then, that fundamental, long-standing aspects of her person can be seen in her negotiation of personas for women health professionals who, like her, traversed the boundaries of medicine and preventive public health. These personas, at their core, reflect Baker's attempt to unite traditional beliefs and practices (e.g., rational thought; scientific motherhood) with those that are more iconoclastic (e.g., intuition; an egalitarian, flexible concept of scientific motherhood). 


\section{Moving Beyond the Health Professions: Personas for the Executive WOMAN PROFESSIONAL}

In closing, I want to briefly examine Baker's construction of self and personas within the concurrent autobiographical self-fashioning of professional women, generally. Applegarth (2015) explains that women's vocationally focused lifewriting was quite popular in the U.S. during the interwar period. Typically written by and for women, vocational autobiographies chronicled women's careers in the human, natural, and applied sciences as well as other fields, like the arts (Applegarth 2015, p. 523). They "focused on a writer's...training, career choices, educational experiences, relationships with mentors and colleagues, and excitement about and commitment to her work" (Applegarth 2015, p. 531). While Applegarth (2015) does not address Fighting for Life at length in her analysis of interwar vocational autobiography, she does identify Baker's text as an example of this genre (p. 549). Baker also invites a similarly broader view of her professional self and its autobiographical retelling. At one point her text, for instance, she speculates that

whether [she] had started in a biscuit factory or a profession or a suburban kitchen, [she] would have probably ended up behind a desk somewhere making the telephone and a staff of assistants jump around in the interest of some widespread scheme or another. (Baker 1939, p. 110)

Vocational autobiographies sought to normalise women's presence in the professional sphere (Applegarth 2015, p. 533). One strategy involved framing women's achievements as the result of hard work and "average talents" in order to contest the notion that professional women were "unnatural in their desires and ambitions" (Applegarth 2015, p. 540; p. 541). ${ }^{3}$ Baker in Fighting for Life similarly emphasizes that her achievements stemmed from hard work as opposed to an inherent (and possibly aberrant) "specialness." An illustration of this point is beyond the scope of my article; however, what bears mentioning is that, along with linking her professional success to hard work, Baker acknowledges the role of luck. The importance of happenstance becomes the most visible in Fighting for Life when Baker describes her entrance into both medicine and public health. As we have seen, Baker decided to study medicine in response to her father's sudden death and her family's subsequent, unexpected financial decline (1939 p. 25). Furthermore, and as we also have seen, Baker claims to have first learned about employment opportunities with New York City's Health department "by accident" (1939, p. 54). Thus, by refusing to embrace hard work as the sole explanation for her professional achievements, Baker reminds her readers that some obstacles, like gender bias, cannot always be surmounted by dedication alone (Hansen 2002).

Although Baker suggests in Fighting for Life that hard work ultimately is an inadequate determinant of women's professional success, she still believes that women professionals have the ability to ascend to the highest posts in their field. Baker has done so herself, and in the conclusion to her autobiography, she enumerates the exact contours of the "pioneer aspect of [her] work" (1939, p. 246). She was the:

first woman to earn the degree of Doctor of Public Health, the first woman to hold an executive government position, the first woman to be appointed in the professional rank in the League of Nations, and above all, the first woman (or man for that matter) to act on the idea that preventive medicine in baby and child care [sic] was a function of government. (Baker 1939, p. 246)

She rose to such heights because she bravely, shrewdly, and compassionately entered scientific and professional territories in which no one had staked out a claim (Baker 1939, p. 247). But 
Baker does not only define herself in this way: Speaking of her female contemporaries in preventive public health, she notes that they "had a tremendous technical advantage in the fact that [they] were pioneering" and willing to entertain areas "men had never bothered to explore" (1939, p. 108, 103). To be "pioneering" in any professional field, then, means rising to a position of power through counterbalancing constraining social beliefs, structural forces and personal circumstances with hard work, luck, moral concern, and unconventional thinking.

\section{CONCLUSION}

To summarise, I used "scientific personas" as a framework for exploring how Dr. Sara Josephine Baker, a U.S.-based physician and expert in well-baby and well-child care, enacts models for women health professionals in her 1939 autobiography Fighting for Life. During the late nineteenth and early twentieth centuries, women like Baker often simultaneously participated in the research, practice, and administration of not only medicine, but also the burgeoning field of preventive public health. As such, "scientific personas" becomes a novel yet apt framework for illuminating women health professionals' collective understanding of their crossdisciplinary work. As I have shown, Baker adopts, reframes, and sometimes significantly alters the prevailing personas for white women physicians, which tended to coalesce around two competing notions: On the one hand, medicine was a scientific pursuit that led to financial success and personal renown; on the other hand, medicine was a moral calling for which women were naturally suited based on their inherent sense of justice and sympathy (MorantzSanchez 1985). Viewing Baker's engagement with these models within the context of her autobiography is especially productive. Autobiographical discourse records and facilitates the formation of identity and persona, and it also illuminates the ways in which identity and persona shape and are shaped by subjective experience as well as historical and social context (Algazi 2016; Eakin 1985; Paul 2016; Smith 1995). Furthermore, as noted by Applegarth (2015), Baker's Fighting for Life participates in the interwar vocational autobiography genre, and approaching her text in this way illustrates how she also was attempting to make sense of American women's role in the professional sphere, in general.

Essentially, in Fighting for Life, Baker's self and persona are portrayed as being motivated by financial need, an interest in science, and moral concerns; however, by highlighting constraining notions of gender and other systemic issues, Baker redefines what these goals look like in actual practice. Thus, while Baker largely adopts prevailing personas for women health professionals to make sense of her work as a physician, in order to conceive of her path-breaking work in preventive health, she substantially alters the dominant models for women physicians. In doing so, she perhaps contributes to the creation of new personas. This especially is evident in her radical refiguring of scientific, expert, and intuitive thinking within a particular approach to caretaking known as scientific motherhood (Apple 2006; Grant 1998). In a similar vein, Baker substantially redefines the ways in which women professionals, in general, conceptualised their success. Ultimately, viewing Baker's Fighting for Life in the somewhat surprising context of scientific personas perhaps encourages us to rethink the ways that identity formation, gender roles, and interstitial professional locations influence the migration, interpretation, and creation of scientific personas. 


\section{END NOTES}

${ }^{1}$ To be sure, xenophobia is present in Fighting for Life, especially regarding Baker's contact with Irish immigrants (Apple 2006; Grant, 1998; Leavitt 1996). But, it lessens as Baker narrates her latter years as a public health official.

${ }^{2}$ I do not meant to imply that her autobiography provides the most authoritative account of the Little Mothers' Leagues. Instead, it offers a subjective view that holds special value in the context of my analysis of person and persona.

${ }^{3}$ Vocational autobiographies also legitimized women as professionals by depicting their literal bodies in professional spaces. Contemporary critics of Fighting for Life often mention Baker's depiction of her physical body at work, and they particularly note her professional attire (Harris 1995; Morantz-Sanchez 1985; More, Fee, \& Parry 2009). Baker's shirtwaists and tailored suits admittedly were inspired by the infamous Gibson Girl, and they may have functioned as "camouflage" for her rejection of traditional gender roles (Baker 1939; Gordon 1987; Patterson 2005). See also Bosch (2016) for a helpful assessment of how scientific personae are realized through women scientists' physical behaviors, including dress.

\section{WORKS CITED}

Algazi, G 2016, 'Three Concepts of the Scholarly Persona', BMGN - Low Countries Historical Review, vol. 131, no. 4, pp. 8-32, retrieved 30 August 2017, <www.bmgn-lchr.nl>.

Apple, R 2006, Perfect Motherhood: Science and Childrearing in America, Rutgers University Press, Rutgers, New Jersey.

Applegarth, R 2015, 'Personal Writing in Professional Spaces: Contesting Exceptionalism in Interwar Women's Vocational Autobiographies', College English, vol. 77, no. 6, pp. 530552, retrieved 5 May 2017, < http://www.ncte.org/journals/ce/issues/v77-6>.

Baker, SJ 1939, Fighting for Life, New York Review of Books, New York.

Bittel, C 2009, 'Mary Putnam Jacobi and the Nineteenth-Century Politics of Women's Health Research,' in E More, E Fee, \& M Parry (eds), Women Physicians and the Cultures of Medicine, The Johns Hopkins University Press, Baltimore, MD, pp. 23-51.

Bosch, M 2016, 'Scholarly Personae and Twentieth-Century Historians: Explorations of a Concept', BMGN - Low Countries Historical Review, vol. 131, no. 4, pp. 33-54, retrieved 5 February 2018, <www.bmgn-lchr.nl>.

Daston, L \& Sibum, 0 2003, 'Introduction: Scientific Personae and Their Histories', Scientific Context, vol. 16, no. 1-2, pp. 1-8, doi:10.1017/S026988970300067X

Division of Child Hygiene 1925, Outlines for Organizing and Directing 'Little Mothers' Leagues', New York State Department of Health, New York, retrieved 29 October 2017, $<$ https://archive.org>.

'Dr. S. Josephine Baker' 2003, U.S. National Library of Medicine, retrieved 12 September 2017, <https://cfmedicine.nlm.nih.gov/physicians/biography_19.html>.

Eakin, P 1985, Fictions in Autobiography, Princeton University Press, Princeton, New Jersey. Epstein, H 2013 'Introduction' in Baker, S, Fighting for Life, pp. vii-xviii.

Fee, E \& Greene, B 1989, 'Science and Social Reform: Women in Public Health', Journal of Public Health Policy, vol. 10, no. 2, pp. 161-177, doi: 10.2307/3342677

Feld, R 1939, 'Pioneering for Public Health', New York Times, 14 May, retrieved 10 September 2017, ProQuest Historical Newspapers.

Gordon, L 1987, 'The Gibson Girl Goes to College: Popular Culture and Women's Higher Education in the Progressive Era, 1890-1920', American Quarterly, vol. 39, no. 2, pp. 211230, doi: $10.2307 / 2712910$ 
Grant, J 1998, Raising Baby by the Book: The Education of American Mothers, Yale University Press, New Haven, Connecticut.

Hardman, P 1988, 'The Steward of Her Soul: Elsie Dinsmore and the Training of a Victorian Child', American Studies, vol. 29, no. 2, pp. 69-90, retrieved 6 October 2017, $<$ https://journals.ku.edu/amerstud/article/view/2492/3478>.

Hansen, B 2002, 'Public Careers and Private Sexuality: Some Gay and Lesbian Lives in the History of Medicine and Public Health', American Journal of Public Health, vol. 92, no. 1, pp. 36-44, doi:10.2105/AJPH.92.1.36

Harris, A 1995, Broken Patterns: Professional Patterns and the Quest for a New Feminine Identity, Wayne State University Press, Wayne, Michigan.

Johnson, EP 2011 'Queer Epistemologies: Theorizing the Self from a Writerly Place Called Home', Biography, vol. 24, no. 3, pp. 429-446, doi:10.1353/bio.2011.0040

Kehily, MJ 1995, 'Self-narration, Autobiography and Identity Construction,' Gender \& Education, vol. 7, no. 1, pp. 23-32, doi:10.1080/713668459

Kleinschmidt, H 1926, 'Little Mothers' Leagues: A Long-Distance View', Journal of Social Hygiene, vol. 9, no. 3, retrieved 13 November 2015, Home Economics Archive: Research, Tradition, History database.

Leavitt, J 1996, Typhoid Mary: Captive to the Public Health, Beacon Press, Boston.

Lejeune, P 1989, On Autobiography, trans. K Leary, ed. P Eakin, University of Minnesota Press, Minneapolis, MN.

'Little Mothers Write Playlets with Helpful Plots' 1910, New York Times, 10 July, p. SM9, retrieved 15 November 2016, ProQuest Historical Newspapers.

Meckel, RA 1990, Save the Babies: American Public Health Reform and the Prevention of Infant Mortality, 1850-1929, The Johns Hopkins University Press, Baltimore, MD.

Moldow, G 1987, Women Doctors in Gilded-Age Washington: Race, Gender, and Professionalization, University of Illinois Press, Urbana, IL.

Morantz-Sanchez, R 1985, Sympathy and Science: Women Physicians in American Medicine, Oxford University Press, Oxford.

More, E 1999, Restoring the Balance: Women Physicians and the Profession of Medicine, 18501995, Harvard University Press, Cambridge, MA.

More, Fee, \& Parry 2009 'Introduction: New Perspectives on Women Physicians and Medicine in the United States, 1859 to the Present, in E More, E Fee, \& M Parry (eds), Women Physicians and the Cultures of Medicine, The Johns Hopkins University Press, Baltimore, MD, pp. 1-22.

Parry, M 2006, 'Sara Josephine Baker (1873-1945)', American Journal of Public Health, vol. 96, no. 4, retrieved 6 October 2017, NCBI.

Patterson, M 2005, Beyond the Gibson Girl: Reimagining the American New Woman, 1895-1915, The University of Illinois Press, Urbana, IL.

Paul, H 2016, 'Introduction: Repertoire and Performances of Academic Identity, BMGN - Low Countries Historical Review, vol. 131, no. 4, pp. 3-7, retrieved 5 February 2018, $<$ www.bmgn-lchr.nl>.

Petrash, A 2016, New York's Remarkable Women: Daughters, Wives, Sisters, and Mothers Who Shaped History, Globe Pequot, New York.

'Planning to Teach' 1909, New York Times, 16 May, p. 20, retrieved 15 November 2016, ProQuest Historical Newspapers.

Rennert, E 1916, 'Little Mothers' Leagues of New York State', The American Journal of Nursing, vol. 16, no. 4, pp. 306-310, retrieved 1 April 2016, $<$ http://www.jstor.org/stable/3406000>.

Smith, S 1995, 'Performativity, Autobiographical Practice, Resistance,' a/b: Auto/Biography Studies, vol. 10, no. 1, pp. 17-33, doi:10.1080/08989575.1995.10815055

Smith, S \& Watson, J 2002, 'Introduction' in S Smith and J Watson (eds), Interfaces: Women/Autobiography/Image/Performance, University of Michigan Press, Ann Arbor, Michigan, pp. 1-44. 
Persona Studies 2018, vol. 4, no. 1

Spargo, J 1907, The Bitter Cry of the Children, Macmillan, New York, retrieved 15 October 2017, <www.books.google.com.>

Skinner, C 2014, Women Physicians and Professional Ethos in Nineteenth-Century America, Southern Illinois University Press, Carbondale, IL.

Tuchman, A 2009, 'Maternity and the Female Body in the Writings of Dr. Marie Zakrzewska, 1829-1902', in E More, E Fee, \& M Parry (eds), Women Physicians and the Cultures of Medicine, The Johns Hopkins University Press, Baltimore, MD, pp. 52-68.

Wu, J 2009, 'A Chinese Woman Doctor in Progressive Era Chicago', in E More, E Fee, \& M Parry (eds), Women Physicians and the Cultures of Medicine, The Johns Hopkins University Press, Baltimore, MD, pp. 89-112.

Zuger, A 2013, 'A Life in Pursuit of Health', New York Times, 28 October, retrieved 17 October 2017, www.nytimes.com. 